\title{
Hierarchical Semiconductor Oxide Photocatalyst: A Case of the $\mathrm{SnO}_{2}$ Microflower
}

\author{
Yang Liu, Yang Jiao, Bosi Yin, Siwen Zhang, Fengyu Qu, Xiang Wu*
}

(Received 27 July 2013; accepted 13 September 2013; published online 8 October 2013)

\begin{abstract}
Hierarchically assembled $\mathrm{SnO}_{2}$ microflowers were synthesized by a facile hydrothermal process. Field emission scanning electron microscope results showed these hierarchical nanostructures were built from two dimensional nanosheets with the thicknesses of about $50 \mathrm{~nm}$. Photoluminescence spectrum of the asobtained products demonstrated a strong visual emission peak at $564 \mathrm{~nm}$. The photochemical measurement results indicated that the as-prepared sample exhibits excellent photocatalytic performance. These three dimensional $\mathrm{SnO}_{2}$ hierarchical nanostructures may have potential applications in waste water purification.
\end{abstract}

Keywords: $\mathrm{SnO}_{2}$; Hierarchical structures; Photocatalyst

Citation: Yang Liu, Yang Jiao, Bosi Yin, Siwen Zhang, Fengyu Qu and Xiang Wu, "Hierarchical Semiconductor Oxide Photocatalyst: A Case of the $\mathrm{SnO}_{2}$ Microflower", Nano-Micro Lett. 5(4), $234-241$ (2013). http://dx.doi.org/10.5101/nml.v5i4.p234-241

In recent years, the semiconductor photocatalysts with high performances for water contaminant degradation have attracted great interest to solve energy and environmental issues. The purification of waste water by photocatalytic degradation of organic dyes using semiconductor nanocrystals has been proven a very effective method [1-11]. As an important direct wide band gap semiconductor $(E g=3.6 \mathrm{eV}), \mathrm{SnO}_{2}$ possesses the excellent optical, gas sensing and photocatalytic properties [12-17]. Thus far, the reported $\mathrm{SnO}_{2}$ nanostructures are mostly one dimensional (1D) structures, such as nanorods [18-20], nanotubes [21-23], and nanowires [24-27] and so on. Only a few successful examples of $\mathrm{SnO}_{2}$ nanosheets have been reported [28-30], which may be attributed to the difficulty in controlling the oxidation process of $\mathrm{Sn}^{2+}$ to $\mathrm{Sn}^{4+}$ such that the mixed phases of $\mathrm{SnO}_{2}$ and $\mathrm{SnO}$ will coexist in the product [31]. Nevertheless, three dimensional (3D) hierarchical structures by self-assembly of nanosheets building blocks are much more relatively rare [32,33]. Due to the complicated spatial arrangement, the hierarchical architectures can provide both extraordinarily high activated surface area and robustness. It is thus highly desirable to develop a facile and efficient method to fabricate phase-pure nanosheets assembled $\mathrm{SnO}_{2}$ hierarchical structures.

In this paper, we reported the synthesis of $\mathrm{SnO}_{2}$ hierarchical architectures by a simple hydrothermal route without the assistant of any templates and surfactants at mild temperature. The effects of growth parameters on morphologies were investigated. A possible growth mechanism of $\mathrm{SnO}_{2}$ hierarchical structures was proposed. The photocatalytic results indicate the assynthesized products may have potential applications in water contaminant treatment.

In a typical synthesis, $6 \mathrm{mmol}$ of $\mathrm{NH}_{4} \mathrm{~F}$ was dissolved in $50 \mathrm{~mL}$ of de-ionized water, followed by the addition of $2 \mathrm{mmol}$ of $\mathrm{SnSO}_{4}$, The solution was then transferred into an $100 \mathrm{~mL}$ Teflon-lined stainless steel autoclave, and kept at $180^{\circ} \mathrm{C}$ for $16 \mathrm{~h}$. After the hydrothermal procedure, the autoclave was cooled naturally down to room temperature. The yellow-green precipitates were collected by centrifugation, then washed several times with distilled water and absolute ethanol, respectively,

Key Laboratory for Photonic and Electronic Bandgap Materials, Ministry of Education and College of Chemistry and Chemical Engineering, Harbin Normal University, Harbin 150025, P. R. China

*Corresponding author. E-mail: wuxiang05@gmail.com 
and dried in air at $60^{\circ} \mathrm{C}$ for $12 \mathrm{~h}$. Finally, the products were annealed in a muffle kiln at $600^{\circ} \mathrm{C}$ for $2 \mathrm{~h}$.

The crystalline structure of the as-obtained products was characterized using X-ray powder diffraction (XRD, Rigaku Dmax-rB, CuK $\alpha$ radiation, $\lambda=0.1542$ $\mathrm{nm}, 40 \mathrm{kV}, 100 \mathrm{~mA}$ ). The morphology and microstructure of the samples were characterized by scanning electron microscope (SEM, Hitachi-4800).

The photocatalytic experiments of the as-prepared products were conducted as follows: $0.1 \mathrm{~g}$ of $\mathrm{SnO}_{2}$ microflowers were suspended in $200 \mathrm{~mL}$ methylene blue (MB) aqueous solution $(40 \mathrm{mg} / \mathrm{L})$. The solution was continuously stirred for $60 \mathrm{~min}$ in the dark to ensure the establishment of an adsorption-desorption equilibrium among the products and MB. After that, the solution was exposed to UV irradiation from a $500 \mathrm{~W}$ Hg lamp at room temperature. The samples were collected at regular time interval to measure the organic dyes degradation by UV-Vis spectra. Subsequently, the experiments of the photocatalytic degradation of eosin red aqueous solution and Congo red (CR) aqueous solution also were conducted in the same conditions.

Figure 1(a) shows XRD pattern of the as-synthesized products. All the diffraction peaks can be indexed to the rutile tetragonal $\mathrm{SnO}_{2}$ in accordance with the stan- dard PDF card (No. 41-1445). No obvious diffraction peaks from other impurities are detected, indicating high purity of the as-synthesized product. To further study the crystallization of the obtained product, room temperature photoluminescence (PL) property of the obtained $\mathrm{SnO}_{2}$ hierarchical structures was measured as well (Fig. 1(b)). Only a strong yellow emission band at $\sim 564 \mathrm{~nm}$ was observed. It is known that the energy gap of bulk $\mathrm{SnO}_{2}$ is $3.6 \mathrm{eV}$. The intrinsic emission peak $(\sim 360 \mathrm{~nm})$ of the $\mathrm{SnO}_{2}$ nanosheets was not found. The strong luminescence emission band from the synthesized products might be related to crystal defects which were produced during the growth [34-40]. During the $\mathrm{SnO}_{2}$ nanosheets growth, a high density of oxygen vacancies, which may mainly locate on the surface of the nanosheets, interact with interfacial tin vacancies, and lead to formation of a considerable amount of trapped states within the bandgap. The results are consistent with previous reports [41]. The morphologies and microstructures of the products were characterized by SEM. Plentiful of flower-like structures assembled by sheet-like subunits with an overall diameter of $\sim 1$ $\mu \mathrm{m}$ could be observed in Fig. 1(c). With a closer examination (Fig. 1(d)), the relatively rigid nanosheets constituents possess a very smooth surface and a thickness of only tens of nanometers.
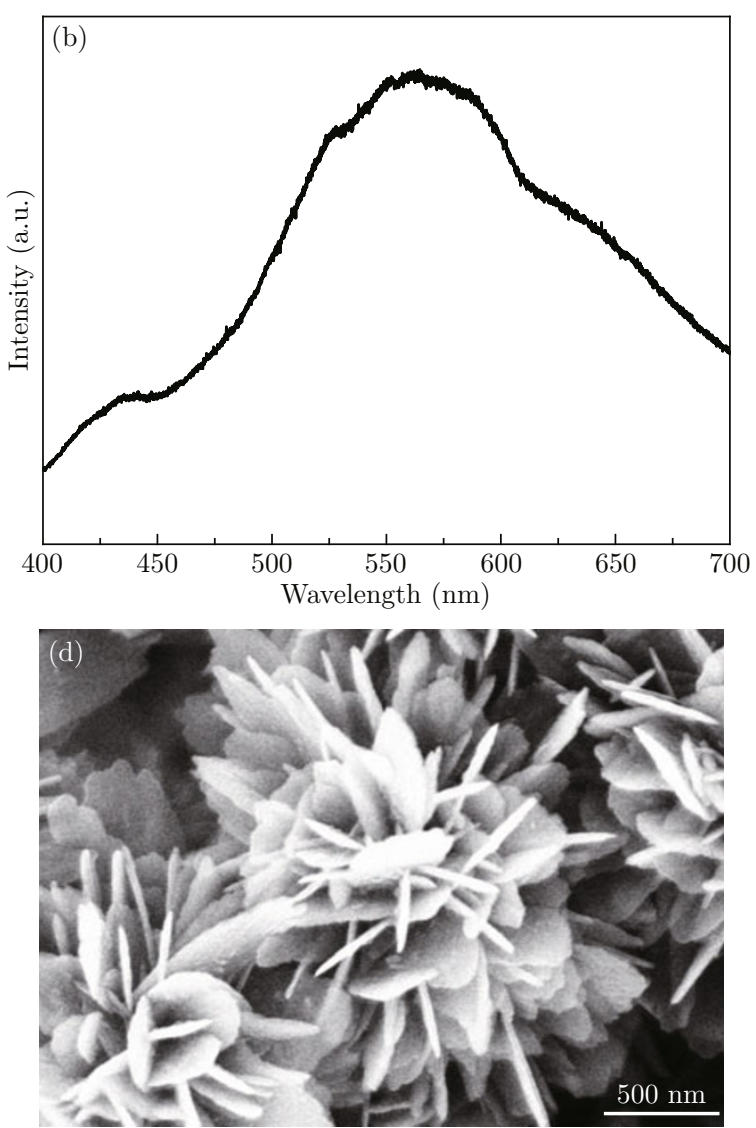

Fig. 1 (a) XRD pattern of the as-synthesized $\mathrm{SnO}_{2}$ microflowers; (b) Photoluminescence spectrum of the as-obtained $\mathrm{SnO}_{2}$ product; (c)-(d) SEM images of the as-synthesized $\mathrm{SnO}_{2}$ architectures at different magnification. 
To investigate formation mechanism of the asobtained $3 \mathrm{D} \mathrm{SnO}_{2}$ structures, effect of reaction time on the morphology of the product were also investigated (Fig. 2). After $0.5 \mathrm{~h}$ of hydrothermal reaction, only small unordered particles were obtained. With the increase of hydrothermal time to $1 \mathrm{~h}$, the small particle-like structures almost completely disappeared, and sheet-like shapes appeared. The sheets were also free of aggregation (Fig. 2(b)). Further increasing the reaction time to $8 \mathrm{~h}$, these sheets were assembled into flower-like nanostructures (Fig. 2(c)). The morphology of the final product is shown in Fig. 2(d). It is clear that much more sheets were assembled into flower clusters, and the typical 3D flower-like structured $\mathrm{SnO}_{2}$ was formed. The degree of assembly increased with
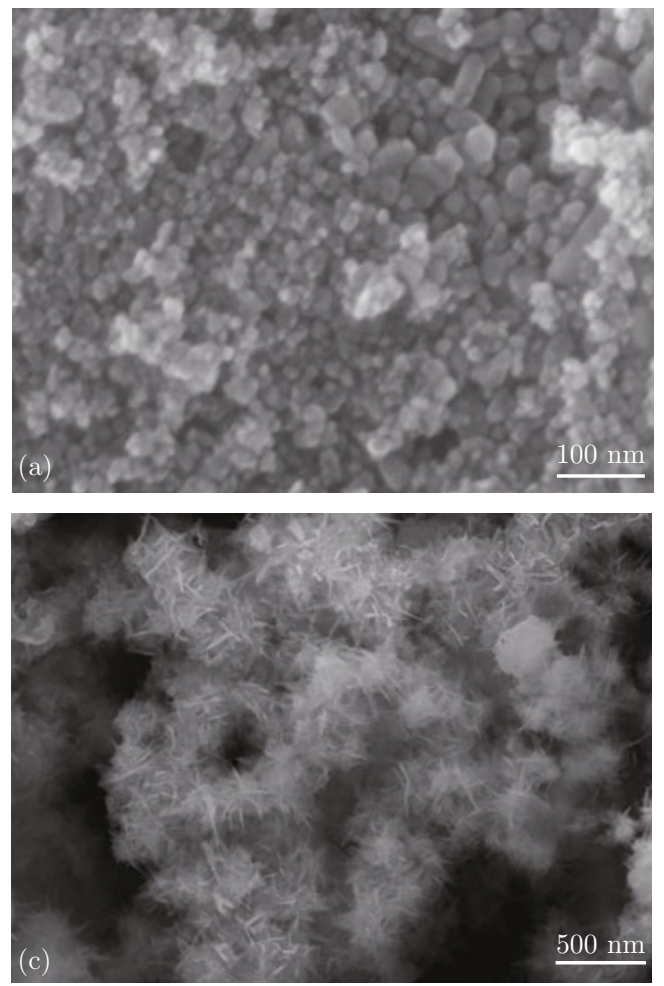

increasing hydrothermal treatment time to $16 \mathrm{~h}$. From Fig. 2(a)-(d), one can clearly see the process of selfassembling growth from nanosheets to microflowers.

On the basis of the above experiment results, the process of the morphology evolution of $\mathrm{SnO}_{2}$ microflowers is summarized in Fig. 3. First the small $\mathrm{SnO}_{2}$ particles were gained via a short hydrothermal process. With the ongoing of the reaction, the primary nanoparticles further grew to the nanosheets, and the freshly formed nanoparticles will spontaneously "land" on the as-formed sheets and then undergo further growth to another sheet, forming a complex structure. These processes could be related to a proposed mechanism of the so-called "orientated attachment" $[42,43]$. In this mechanism, the larger particles are grown from small
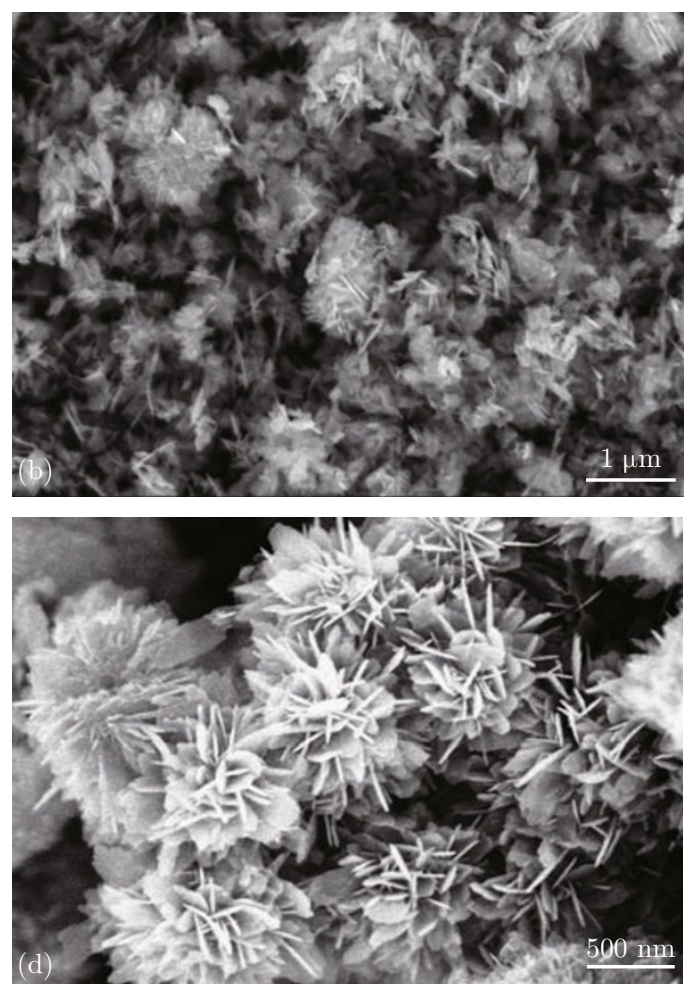

Fig. 2 SEM images of the as-obtained products at $180^{\circ} \mathrm{C}$ for (a) $1 \mathrm{~h}$; (b) $4 \mathrm{~h}$; (c) $8 \mathrm{~h}$; and (d) $16 \mathrm{~h}$.

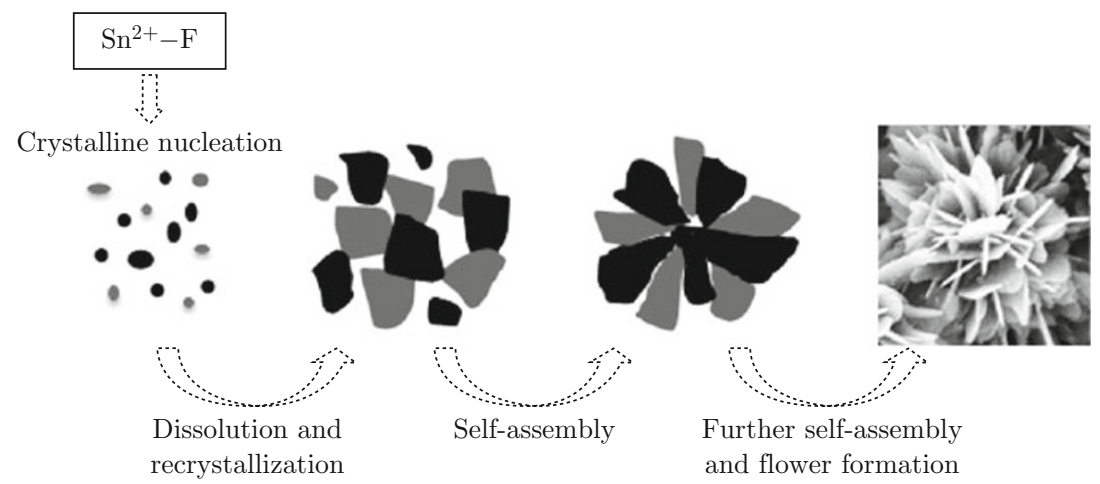

Fig. 3 Schematic illustration of the possible formation and morphology evolution of $3 \mathrm{D}$ structured $\mathrm{SnO}_{2}$ microflowers. 
primary nanoparticles through an orientated attachment process, in which the adjacent nanoparticles are self-assembled by sharing a common crystallographic orientation and docking of these particles at a planar interface. Small particles may aggregate in an oriented fashion to produce a larger single crystal, or they may aggregate randomly and reorient, recrystallize, or undergo phase transformations to produce larger single crystals. This type of growth mode could lead to the formation of faceted particles or anisotropic growth if there is sufficient difference in the surface energies of different crystallographic faces. In our case, according to the experimental results, the latter seems to be more reasonable. Therefore, the formation of the $\mathrm{SnO}_{2}$ microflowers can be rationally expressed as a kinetically controlled nucleationdissolution-recrystallization mechanism for three steps in sequence: (1) the hydrothermal-induced formation of primary nanoparticles, (2) with time increasing, hydrothermal-induced fusion of these primary nanoparticles accompanying the oriented growth to form the sheet-like structure, and (3) a further growth and crystallization process, giving rise to the formation of the
3D flower-like products. Although the exact formation mechanism for this complex nanostructure is not yet clear, it is believed that the growth of the flowerlike nanostructures is not catalyst-assisted or templatedirected, because the only material sources used in our synthesis are pure oxide crystals and $\mathrm{NH}_{4} \mathrm{~F}$ [44].

The photocatalytic activities of the as-obtained hierarchical $\mathrm{SnO}_{2}$ microflowers can be evaluated by degrading $\mathrm{MB}$, eosin red and $\mathrm{CR}$ in aqueous solutions under UV irradiation, respectively. Figure 4(a) shows the adsorption spectrum of $\mathrm{MB}$ in aqueous solution using $\mathrm{SnO}_{2}$ microflowers as the photocatalysts under a 500 $\mathrm{W}$ mercury lamp. It was proved that the characteristic absorption peak $(665 \mathrm{~nm})$ decreases gradually with the increase of illumination time. MB is degraded $98 \%$ when the radiation time reached $20 \mathrm{~min}$. The adsorption spectrum of eosin red in aqueous solution under the same conditions is shown in Fig. 4(b). It demonstrates that the concentration of eosin red is decreased as the irradiation time increases by measuring the intensity of the characteristic absorption peak $(517 \mathrm{~nm})$, and degraded $92 \%$ after $20 \mathrm{~min}$. Finally, a further comparison was made to investigate the photocatalytic activity of
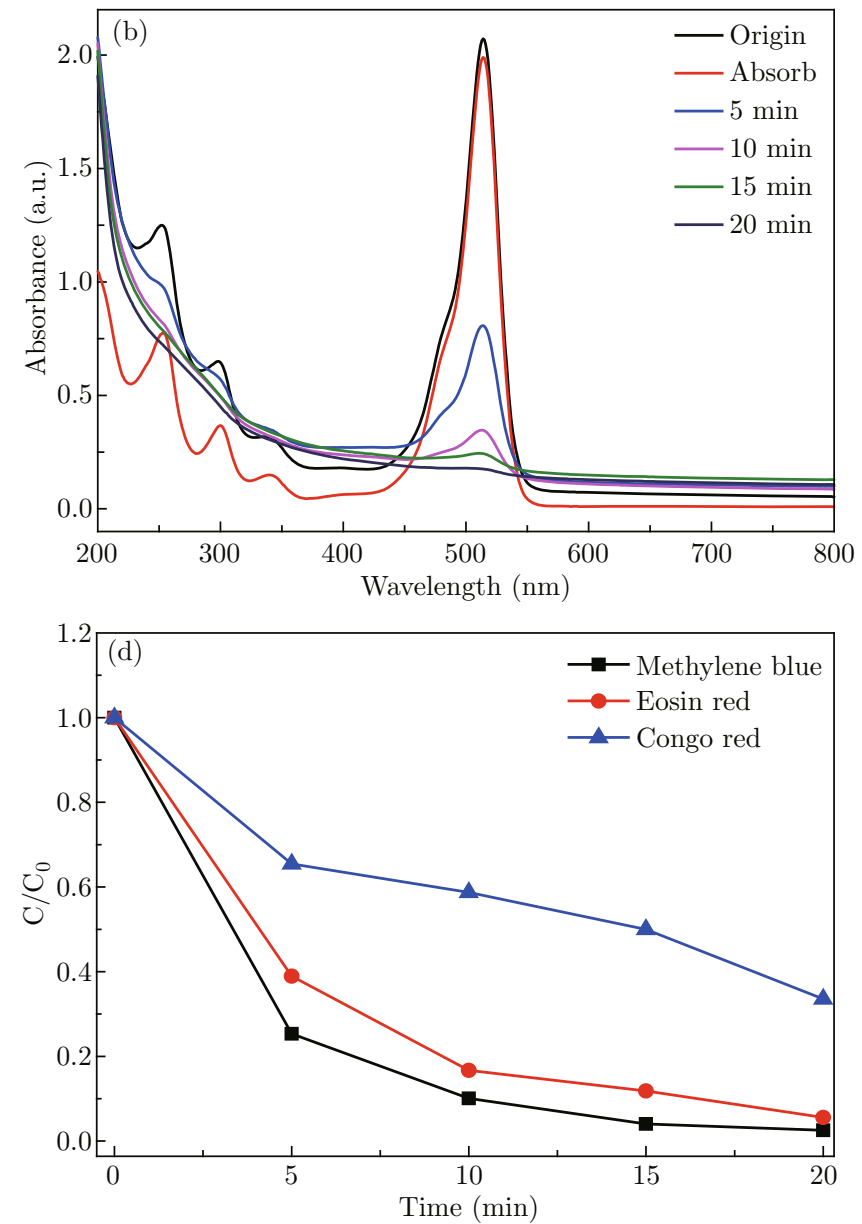

Fig. 4 (a)-(c) Variations of adsorption spectra of organics dye solution in the presence of the $\mathrm{SnO}_{2}$ microflowers irradiated by a UV lamp for different time (a) Methylene blue; (b) Eosin red; (c) Congo red; (d) Degradation rate curves. 
the $\mathrm{SnO}_{2}$ nanostructures in the degradation of $\mathrm{CR}$ in an aqueous solution. The intensity of the characteristic adsorption peak (496 nm) of CR diminished gradually with extension of the exposure time (see Fig. 4(c)), decomposing to about $83 \%$ after 40 min irradiation. The results suggest that the as-prepared $\mathrm{SnO}_{2}$ microflowers exhibit excellent photocatalytic activity for $\mathrm{MB}$, eosin red and CR. In order to prove $\mathrm{SnO}_{2}$ nanostructures are highly selective to what type of dye molecule, we took the same first $20 \mathrm{~min}$ to contrast the degradation efficiency of different dyes. The results reveal the order of degradation rate is MB $(98 \%)>$ eosin red $(92 \%)>$ CR (82\%) in Fig. 4(d). It indicates that degradation efficiency of MB is higher than eosin red and CR.

In order to probe into how the morphology and structure of the photocatalyst affect the efficiency of photocatalysis, the photocatalytic experiments were conducted for the degradation of MB in water under UV irradiation in the presence of three different morpholo-
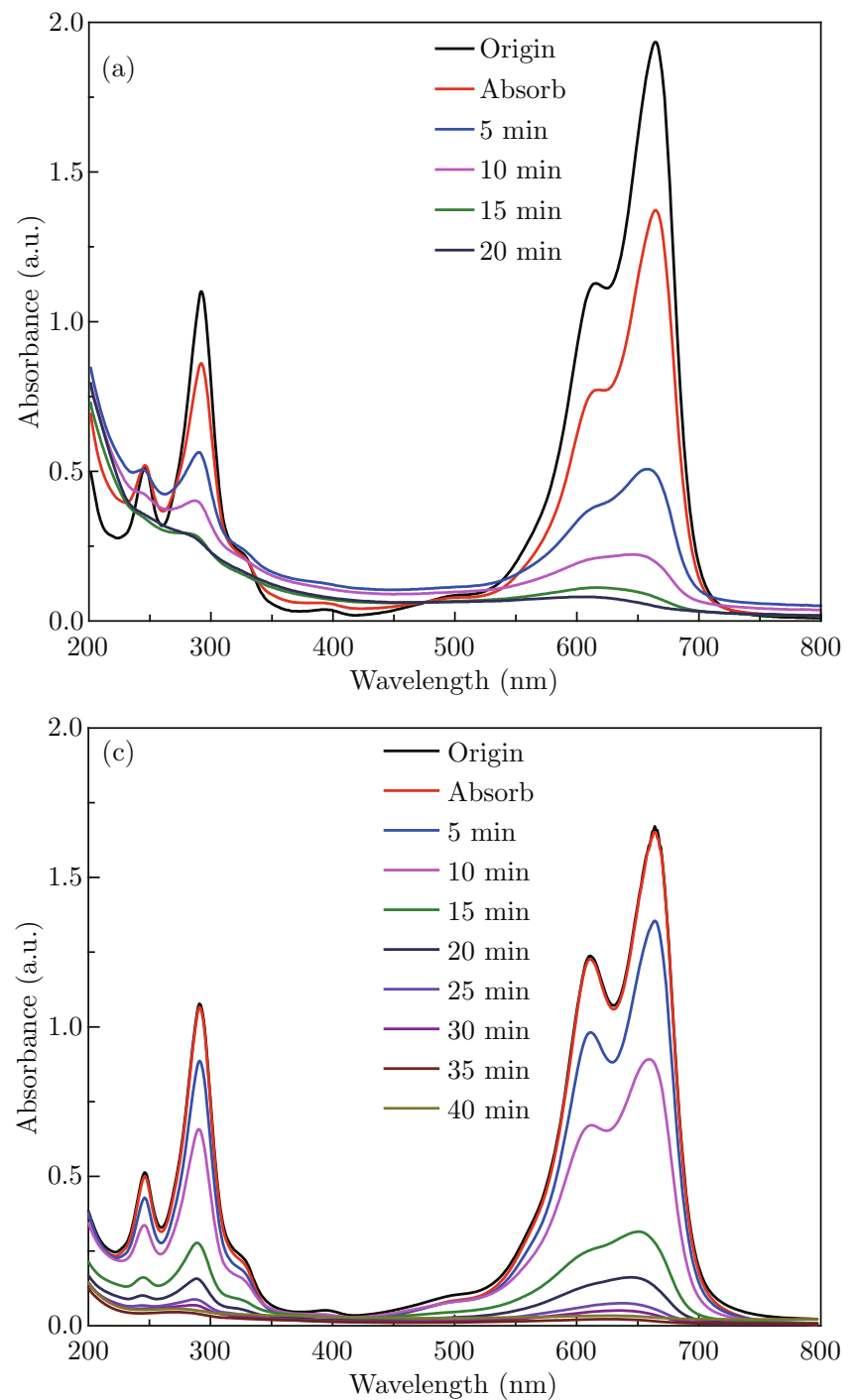

gies of $\mathrm{SnO}_{2}$ : microflowers, commercial $\mathrm{SnO}_{2}$ powder and $\mathrm{ZnO}$ microflowers. Figure 5(a) shows the adsorption spectra of $\mathrm{MB}$ solution in the presence of $\mathrm{SnO}_{2}$ hierarchical structures under UV light irradiation. The main absorption peak of MB centered at $665 \mathrm{~nm}$ before and after irradiation. The MB aqueous solution was degraded almost completely when the irradiation time reached 20 min. Figure 5(b) shows the adsorption spectra of MB solutions in the presence of commercial $\mathrm{SnO}_{2}$ powder, its photocatalytic degradation rate is $89 \%$ in $210 \mathrm{~min}$. To compare with the degradation efficiencies of the other photocatalysts, the photocatalytic experiments of $\mathrm{ZnO}$ microflowers was conducted by degrading MB under the same experimental conditions [9]. The adsorption spectra of $\mathrm{MB}$ in aqueous solution are shown in Fig. 5(c). Degradation rate curve of $\mathrm{SnO}_{2}$ microflowers, commercial powder and $\mathrm{ZnO}$ microflowers are shown in Fig. 5(d). It is quite clear that under identical experimental conditions, the
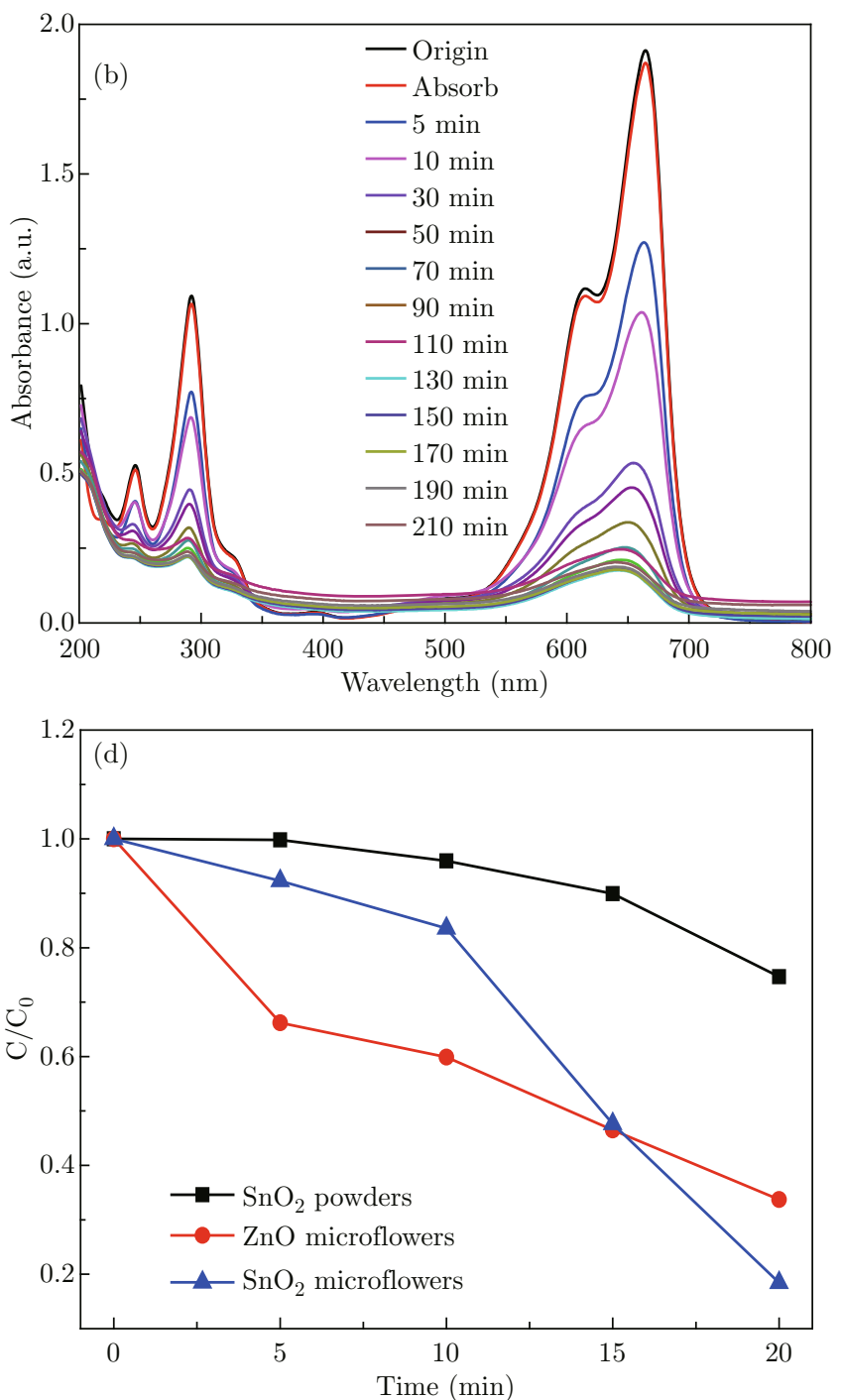

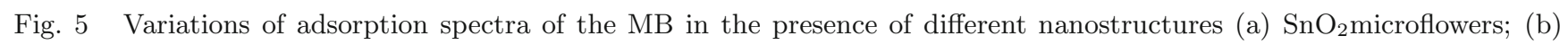
Commercial $\mathrm{SnO}_{2}$ powder; (c) $\mathrm{ZnO}$ microflowers; (d) Degradation rate curve. 
hierarchical $\mathrm{SnO}_{2}$ structures exhibited superior photocatalytic activity compared to $\mathrm{SnO}_{2}$ powder and $\mathrm{ZnO}$ microflowers. Such excellent photocatalytic activities can be attributed to the several outstanding features of the $\mathrm{SnO}_{2}$ microflowers, including the large surface volume ratio, the effective electron hole separation of the Schottky barriers and thickness of $\mathrm{SnO}_{2}$ sheets. It might be that higher surface area increases the number of active sites and promotes separation efficiency of the electron-hole pairs, resulting in the improvement of photocatalytic activity. And the separation and mobility of the electron-hole pairs were intensely suppressed in wide band gap [45-48]. Hence, flower-like $\mathrm{SnO}_{2}$ with large surface area and wide band gap possess the highest photocatalytic activity among various $\mathrm{SnO}_{2}$.

In summary, uniform 3D structured $\mathrm{SnO}_{2}$ microflowers have been successfully synthesized via a facile hydrothermal process at low temperature in the absence of any surfactants. The hierarchical $\mathrm{SnO}_{2}$ microflowers were assembled by the nanosheets with thickness about $50 \mathrm{~nm}$. The possible growth mechanism of $\mathrm{SnO}_{2}$ nanostructures is proposed based on the experimental results. The investigation into the photocatalytic performences demonstrated that the hierarchical $\mathrm{SnO}_{2}$ microflowers possess a high photocatalytic activity for the degradation of organic dyes under UV irradiation. It is expected that $\mathrm{SnO}_{2}$ architectures may have potential applications in water contaminant degradation.

\section{Acknowledgement}

This work was supported by the Foundation for Key Project of Ministry of Education, China (No. 211046). Program for New Century Excellent Talents in Heilongjiang Provincial University (1252-NCET-018), the Scientific Research Fund of Heilongjiang Provincial Education Department (12531179) and Program for Scientific and Technological Innovation Team Construction in Universities of Heilongjiang (No. 2011TD010).

\section{References}

[1] J. Wang, F. Y. Qu and X. Wu, "Synthesis of ultra-thin $\mathrm{ZnO}$ nanosheets: photocatalytic and superhydrophilic properties", Sci. Adv. Mater. 5(8), 1052-1059 (2013). http://dx.doi.org/10.1166/sam.2013.1554

[2] W. N. Jia, X. Wu, B. X. Jia, F. Y. Qu and H. J. Fan, "Self-assembled porous $\mathrm{ZnS}$ nanospheres with high photocatalytic performance", Sci. Adv. Mater. 5(10), 1329-1336 (2013). http://dx.doi.org/10.1166/sam. 2013. 1593

[3] Z. Yu, X. Wu, J. Wang, W. N. Jia, G. S. Zhu and F. Y. Qu, "Facile template-free synthesis and visible-light driven photocatalytic performances of dendritic CdS hierarchical structures", Dalton Trans.
42(13), 4633-4638 (2013). http://dx.doi.org/10. $1039 / \mathrm{c} 2 \mathrm{dt} 32486 \mathrm{e}$

[4] J. Wang, F. Y. Qu and X. Wu, "Photocatalytic degradation of organic dyes with hierarchical $\mathrm{Ag}_{2} \mathrm{O} / \mathrm{ZnO}$ heterostructures", Sci. Adv Mater. 5(10), 1364-1371 (2013).http://dx.doi.org/10.1166/sam.2013.1597

[5] W. N. Jia, B. X. Jia, F. Y .Qu, X. Wu, Dalton Trans. 42, $14178(2013)$

[6] X. F. Wang, H.T. Huang, B. Liu, B. Liang, C. Zhang, Q Ji, D. Chen and G. Z. Shen, "Shape evolution and applications in water purification: the case of CVD-grown $\mathrm{Zn}_{2} \mathrm{SiO}_{4}$ straw-bundles", J. Mater. Chem. 22, 5330-5335 (2011) http://dx.doi.org/10.1039/ c1jm14551g

[7] L. N. Gao, F. Y. Qu and X. Wu, "Reduced graphene oxide- $\mathrm{BiVO}_{4}$ composite for enhanced photoelectrochemical cell and photocatalysis", Sci. Adv. Mater. 5(10), 1485-1492 (2013).

[8] T. Q. Chang, Z. J. Li, G. Q. Yun, Y. Jia, H. J. Yang, "Enhanced photocatalytic activity of $\mathrm{ZnO} / \mathrm{CuO}$ nanocomposites synthesized by hydrothermal method", Nano-Micro Lett. 5(3), 163-168 (2013). http://dx.doi.org/10.5101/nml.v5i3.p163-168

[9] J. Wang, F. Y. Qu and X. Wu, "Controlled synthesis and photocatalytic properties of three dimensional hierarchical ZnO microflowers", Mater. Express 3(3), 256-264 (2013). http://dx.doi.org/10.1166/ mex. 2013. 1118

[10] K. G. Chandrappa and T. V. Venkatesha, "Electrochemical synthesis and photocatalytic property of zinc oxide nanoparticles", Nano-Micro Lett. 4(1), 1424 (2012). http://dx.doi.org/10.3786/nml.v4i1. p14-24

[11] H. W. Wei, L. Wang, Z. P. Li, S. Q. Ni and Q. Q. Zhao, "Synthesis and photocatalytic activity of onedimensional CdS@ $\mathrm{TiO}_{2}$ core-shell heterostructures", Nano-Micro Lett. 3(1), 6-11 (2011). http://dx.doi. org/10.3786/nml.v3i1.p6-11

[12] Y. T. Han, X. Wu, G. Z. Shen, B. Dierre, L. Gong, F. Y. Qu, Y. Bando, T. Sekiguchi, F. Fabbri and D. Golberg, "Solution growth and cathodoluminescence of novel $\mathrm{SnO}_{2}$ core-shell homogeneous microspheres", J. Phys. Chem. C 114(18), 8235-8240 (2010). http:// dx.doi.org/10.1021/jp100942m

[13] Y. T. Han, X. Wu, Y. L. Ma, L. H. Gong, F. Y. Qu and H. J. Fan, "Porous $\mathrm{SnO}_{2}$ nanowire bundles for photocatalyst and Li ion battery applications", CrystEngComm 13(10), 3506-3510 (2011). http://dx.doi. org/10.1039/c1ce05171g

[14] H. T. Huang, S. Q. Tian, J. Xu, Z. Xie, D. W. Zeng, D. Chen and G. Z. Shen, "Needle-like Zn-doped $\mathrm{SnO}_{2}$ nanorods with enhanced photocatalytic and gas sensing properties", Nanotechnology 23(10), 105502 (2012). http://dx.doi.org/10.1088/0957-4484/23/ 10/105502

[15] B. X. Jia, W. N. Jia, Y. L. Ma, X. Wu and F. Y. $\mathrm{Qu}$, " $\mathrm{SnO}_{2}$ core-shell microspheres with excellent photocatalytic properties", Sci. Adv. Mater. 4(7), 702-707 (2012). http://dx.doi.org/10.1166/sam.2012.1341 
[16] B. X. Jia, W. N. Jia, F. Y. Qu and X. Wu, "Hierarchical porous $\mathrm{SnO}_{2}$ microflowers photocatalyst", Sci. Adv. Mater. 4(11), 1127-1133 (2012). http://dx.doi. org/10.1166/sam.2012.1404

[17] B. X. Jia, W. N. Jia, X. Wu and F. Y. Qu, "General strategy for self assembly of mesoporous $\mathrm{SnO}_{2}$ nanospheres and their applications in water purification", RSC Adv. 3(30), 12140-12148 (2013). http://dx.doi.org/10.1039/c3ra41638k

[18] L. Vayssieres and M. Graetzel, "Highly ordered $\mathrm{SnO}_{2}$ nanorod arrays from controlled aqueous growth", Angew. Chem. 116(28), 3752-3756 (2004). http://dx. doi.org/10.1002/ange. 200454000

[19] Z. Y. Zhang, R. J. Zou, G. S. Song, L. Yu, Z. G. Chen and J. Q. Hu, "Highly aligned $\mathrm{SnO}_{2}$ nanorods on graphene sheets for gas sensors", J. Mater. Chem. 21, 17360-17365 (2011). http://dx.doi.org/ 10.1039/c1jm12987b

[20] Y. L. Wang, M. Guo, M. Zhang and X. D. Wang, "Hydrothermal preparation and photoelectrochemical performance of size-controlled $\mathrm{SnO}_{2}$ nanorod arrays", CrystEngComm 12(12), 4024-4027 (2010). http://dx.doi.org/10.1039/COCE00201A

[21] Y. Liu, Y. Jiao, F. Y. Qu, L. H. Gong and X. $\mathrm{Wu}$, "Facile synthesis of template-induced $\mathrm{SnO}_{2}$ nanotubes", J. Nanomater. 610964 (2013). http://dx. doi.org/10.1155/2013/610964

[22] J. Z. Wang, N. Du, H. Zhang, J. X. Yu and D. Yang, "Large-scale synthesis of $\mathrm{SnO}_{2}$ nanotube arrays as high-performance anode materials of Li-Ion batteries", J. Phys. Chem. C 115(22), 11302-11305 (2011). http://dx.doi.org/10.1021/jp203168p

[23] X. Xu, J. Liang, H. Zhou, D. M. Lv, F. X. Liang, Z. L. Yang, S. J .Ding and D. M. Yu, "The preparation of uniform $\mathrm{SnO}_{2}$ nanotubes with a mesoporous shell for lithium storage", J. Mater. Chem. A 1(9), 2995-2998 (2013). http://dx.doi.org/10.1039/c3ta01372c

[24] M. L. Lu, C. W. Lai, H. J. Pan, C. T. Chen, P. T. Chou and Y. F. Chen, "A facile integration of zero- (I-III-VI quantum dots) and one- (single $\mathrm{SnO}_{2}$ nanowire) dimensional nanomaterials: fabrication of a nanocomposite photodetector with ultrahigh gain and wide spectral response", Nano Lett. 13(5), 1920-1927 (2013). http://dx.doi.org/ 10.1021/nl3041367

[25] H. B. Feng, J. Huang and J. H. Li, "A mechanical actuated $\mathrm{SnO}_{2}$ nanowire for small molecules sensing", Chem. Commun. 49(10), 1017-1019 (2013). http:// dx.doi.org/10.1039/c2cc38463a

[26] X. S. Fang, J. Yan, L. F. Hu, H. Liu, "Thin $\mathrm{SnO}_{2}$ nanowires with uniform diameter as excellent field emitters: a stability of more than 2400 minutes", Adv. Funct. Mater. 22(8), 1613-1622 (2012). http://dx. doi.org/10.1002/adfm. 201102196

[27] L. F. Hu, J. Yan, M. Y. Liao, L. M. Wu, X. S. Fang, "Ultrahigh external quantum efficiency from thin $\mathrm{SnO}_{2}$ nanowire ultraviolet photodetectors", Small 7(8), 1012-1017 (2011). http://dx.doi.org/10.1002/ smll. 201002379
[28] C. Wang, G. H. Du, K. Ståhl, H. X. Huang, Y. J. Zhong and J. Z. Jiang, "Ultrathin $\mathrm{SnO}_{2}$ nanosheets: oriented attachment mechanism, nonstoichiometric defects, and enhanced lithium-Ion battery performances", J. Phys. Chem. C 116(6), 4000-4011 (2012). http://dx.doi.org/10.1021/jp300136p

[29] J. Xing, W. Q. Fang, Z. Li and H. G. Yang, " $\mathrm{TiO}_{2}$ coated ultrathin $\mathrm{SnO}_{2}$ nanosheets used as photoanodes for dye-sensitized solar cells with high efficiency", Ind. Eng. Chem. Res. 51(11), 4247-4253 (2012). http:// dx.doi.org/10.1021/ie2030823

[30] C. Wang, Q. Wu, H. L. Ge, T. Shang and J Z Jiang, "Magnetic stability of $\mathrm{SnO}_{2}$ nanosheets", Nanotechnology 23(7), 075704 (2012). http://dx.doi.org/10. 1088/0957-4484/23/7/075704

[31] H. B. Wu, J. S. Chen, X. W. Lou and H. H. Hng, "Synthesis of $\mathrm{SnO}_{2}$ hierarchical structures assembled from nanosheets and their lithium storage properties", J. Phys. Chem. C 115(50), 24605-24610 (2011). http:// dx.doi.org/10.1021/jp208158m

[32] X. Y. Zhao, M. H. Cao and C. W. Hu, "Binder strategy towards improving the rate performance of nanosheet-assembled $\mathrm{SnO}_{2}$ hollow microspheres", RSC Adv. 2(31), 11737-11742 (2012). http://dx.doi.org/ $10.1039 /$ c2ra21867d

[33] T. H. Lea, Q. D. Truong, T. Kimura, H. H. Li, C. S. Guo, S. Yin, T. Sato and Y. C. Ling, "Construction of $3 \mathrm{D}$ hierarchical $\mathrm{SnO}_{2}$ microspheres from porous nanosheets towards NO decomposition", Solid State Sci. 15, 29-35 (2013). http://dx.doi.org/10.1016/j . solidstatesciences. 2012.09.004

[34] W. F. Li, Y. G. Sun and J. L. Xu, "Controllable hydrothermal synthesis and properties of $\mathrm{ZnO}$ hierarchical micro/nanostructures", Nano-Micro Lett. 4(2), 98102 (2012). http://dx.doi.org/10.3786/nml.v4i2. p98-102

[35] H. Liu, L. F. Hu, K. Watanabe, X. H. Hu, B. Dierre, B. S. Kim, T. Sekiguchi and X. S. Fang, "Cathodoluminescence modulation of $\mathrm{ZnS}$ nanostructures by morphology, doping, and temperature", Adv. Funct. Mater. 23(29), 3701-3709 (2013). http://dx.doi.org/ 10. 1002/adfm. 201203711

[36] H. Chen, X. Wu, L. H. Gong, C. Ye, F. Y. Qu and G. Z. Shen, "Hydrothermally grown $\mathrm{ZnO}$ micro/nanotube arrays and their properties", Nanoscale Res. Lett. 5(3), 570-575 (2010). http://dx.doi.org/ 10.1007/s11671-009-9506-4

[37] L. J. Yu, F. Y. Qu and X. Wu, "Facile hydrothermal synthesis of novel $\mathrm{ZnO}$ nanocubes", J. Alloys Compd. 504(1), L1-L4 (2010). http://dx.doi.org/10.1016/ j.jallcom.2010.05.055

[38] X. Wu, Y. Lei, Y. F. Zheng and F. Y. Qu, "Controlled growth and cathodoluminescence property of ZnS nanobelts with large aspect ratio", Nano-Micro Lett. 2(4), 272-276 (2010). http://dx.doi.org/10. 3786/nml .v2i4.p272-276

[39] Y. Lei, F. Y. Qu and X. Wu, "Assembling ZnO nanorods into microflowers through a facile solution strategy: morphology control and cathodolumines- 
cence properties", Nano-Micro Lett. 4(1),45-51 (2012). http://dx.doi.org/10.3786/nml.v4i1.p45-51

[40] Z. L. Zhang, J. Wang, Z. Yu, F. Y. Qu and X. Wu, "Assembling $\mathrm{SnO}$ nanosheets into microhydrangeas: gas phase synthesis and their optical property", NanoMicro Lett. 4(4), 215-219 (2012). http://dx.doi.org/ 10.3786/nml.v4i4.p215-219

[41] H. B. Zeng, G. T. Duan, Y. Li, S. K. Yang, X. $\mathrm{X}$. $\mathrm{Xu}$ and W. P. Cai, "Blue luminescence of $\mathrm{ZnO}$ nanoparticles based on non-equilibrium processes: defect origins and emission controls", Adv. Funct. Mater. 20(4), 561-572 (2013). http://dx.doi.org/10.1002/ adfm. 200901884

[42] R. L. Penn and J. F. Banfield, "Imperfect oriented attachment: dislocation generation in defectfree nanocrystals", Science 281(5379), 969-971 (1998). http://dx.doi.org/10.1126/science.281.5379.969

[43] J. F. Banfield, S. A. Welch, H. Z. Zhang, T. T. Ebert and R. L Penn, "Aggregation-based crystal growth and microstructure development in natural iron oxyhydroxide biomineralization products", Science 289(5480), 751-754 (2000). http://dx.doi.org/ 10.1126/science.289.5480.751

[44] X. S. Fang, C. H. Ye, L. D. Zhang, J. X. Zhang, J. W. Zhao and P. Yan, "Direct observation of the growth process of $\mathrm{MgO}$ nanoflowers by a simple chemical route", Small 1(4), 422-428(2005). http://dx.doi. org/10.1002/smll. 200400087

[45] H. B. Zeng, W. P. Cai, P. S. Liu, X. X. Xu, H. J. Zhou, C. Klingshirn and H. Kalt, "ZnO-based hollow nanoparticles by selective etching: elimination and reconstruction of metal-semiconductor interface, improvement of blue emission and photocatalysis", ACS Nano 2(8), 1661-1670 (2008). http://dx.doi.org/10. $1021 /$ nn800353q

[46] M. J. Height, S. E. Pratsinis, O.Mekasuwandumrong, P. Praserthdam, "Ag-ZnO catalysts for UVphotodegradation of methylene blue", Appl. Catal. B: Environ. 63(3-4), 305-312 (2006). http://dx.doi. org/10.1016/j. apcatb. 2005.10.018

[47] J. J. Wu and C. H. Tseng, "Photocatalytic properties of nc-Au/ZnO nanorod composites", Appl. Catal. B 66(1-2), 51-57 (2006). http://dx.doi.org/10.1016/ j.apcatb. 2006.02.013

[48] F. Ammari, J.Lamotte and R.Touroude, "An emergent catalytic material: $\mathrm{Pt} / \mathrm{ZnO}$ catalyst for selective hydrogenation of crotonaldehyde", J. Catal. 221(1), 32-42 (2004). http://dx.doi.org/10.1016/ S0021-9517 (03) 00290-2 